\title{
Extracorporeal membrane oxygenation as a bridge to lung transplantation: analysis of Korean organ transplantation registry (KOTRY) data
}

Ryoung-Eun Ko ${ }^{1}$, Jin Gu Lee ${ }^{2}$, Song Yee Kim³ ${ }^{3}$ Young Tae Kim${ }^{4}$, Sun Mi Choi ${ }^{5}$, Do Hyung Kim ${ }^{6}$, Woo Hyun Cho ${ }^{7}$, Seung-II Park ${ }^{8}$, Kyung-Wook Jo ${ }^{9}$, Hong Kwan Kim ${ }^{10}$, Hyo Chae Paik ${ }^{2}$, Kyeongman Jeon ${ }^{1,11^{*}}$ (D) and the Korean Organ Transplantation Registry Study Group

\begin{abstract}
Background: The use of extracorporeal membrane oxygenation (ECMO) as a bridge to lung transplantation has greatly increased. However, data regarding the clinical outcomes of this approach are lacking. The objective of this multicenter prospective observational cohort study was to evaluate lung transplantation outcomes in Korean Organ Transplantation Registry (KOTRY) patients for whom ECMO was used as a bridge to transplantation.

Methods: Between March 2015 and December 2017, a total of 112 patients received lung transplantation and were registered in the KOTRY, which is a prospective, multicenter cohort registry. The entire cohort was divided into two groups: the control group $(n=85,75.9 \%)$ and bridge-ECMO group $(n=27,24.1 \%)$.

Results: There were no significant differences in pre-transplant and intraoperative characteristics except for poorer oxygenation, more ventilator use, and longer operation time in the bridge-ECMO group. The prevalence of primary graft dysfunction at $0,24,48$, and $72 \mathrm{~h}$ after transplantation did not differ between the two groups. Although postoperative hospital stays were longer in the bridge-ECMO group than in the control group, hospital mortality did not differ between the two groups $(25.9 \%$ vs. $13.3 \%, P=0.212)$. The majority of patients (70.4\% of the bridge-ECMO group and $77.6 \%$ of the control group) were discharged directly to their homes. Finally, the use of ECMO as a bridge to lung transplantation did not significantly affect overall survival and graft function.
\end{abstract}

Conclusions: Short- and long-term post-transplant outcomes of bridge-ECMO patients were comparable to recipients who did not receive ECMO.

Keywords: Lung transplantation, Extracorporeal membrane oxygenations, Bridge to transplant, Treatment outcome

\footnotetext{
* Correspondence: kjeon@skku.edu

'Department of Critical Care Medicine, Samsung Medical Center,

Sungkyunkwan University School of Medicine, Seoul, Korea

${ }^{11}$ Division of Pulmonary and Critical Care Medicine, Department of Medicine,

Samsung Medical Center, Sungkyunkwan University School of Medicine, 81

Irwon-ro, Gangnam-gu, Seoul 06351, Korea

Full list of author information is available at the end of the article
}

(c) The Author(s). 2020 Open Access This article is distributed under the terms of the Creative Commons Attribution 4.0 International License (http://creativecommons.org/licenses/by/4.0/), which permits unrestricted use, distribution, and reproduction in any medium, provided you give appropriate credit to the original author(s) and the source, provide a link to the Creative Commons license, and indicate if changes were made. The Creative Commons Public Domain Dedication waiver (http://creativecommons.org/publicdomain/zero/1.0/) applies to the data made available in this article, unless otherwise stated. 


\section{Background}

Lung transplantation has become an accepted treatment for carefully selected patients with end-stage lung disease $[1,2]$. However, due to a shortage of donors, the number of patients on waiting lists is growing rapidly and the average waiting time to lung transplantation has increased [3, 4]. Given these circumstances, there has been a corresponding increase in demand for mechanical ventilation (MV) and extracorporeal membrane oxygenation (ECMO) support to bridge these critically ill patients to lung transplantation.

MV is associated with risks of ventilator-associated pneumonia, ventilator-induced lung injury, and hemodynamic instability [5-8]. Furthermore, recent reports have indicated that waiting for lung transplantation with MV support is a risk factor for increased mortality compared without MV $[9,10]$. Recently, due to advances in critical care management and improvements in technology regarding the safety profile and management of ECMO, the use of ECMO as a bridge to lung transplantation has steadily increased [11-13]. However, bridging to transplantation with ECMO has also been associated with major complications and increased in-hospital mortality $[14,15]$. In addition, $\mathrm{ECMO}$ is invasive, requires anticoagulation for the duration of therapy, and can be associated with serious complications [16, 17]. Therefore, concerns remain about bridging patients with ECMO to lung transplantation. However, most data on lung transplantation after bridging with ECMO is drawn from retrospective, single-institution studies, and data describing long-term outcomes after lung transplantation are limited.

The objective of this study was to evaluate the mortality and long-term post transplantation outcomes of patients undergoing lung transplantation after bridging with ECMO by comparing them with non-bridgeECMO patients through an analysis of Korean Organ Transplantation Registry (KOTRY) data.

\section{Methods}

\section{Study design}

KOTRY is a prospective, multicenter cohort registry that includes kidney, liver, pancreas, heart, and lung transplantations in Korea [18]. Lung transplanted patients from 5 institutions are enrolled in KOTRY. Patients are enrolled at the time of transplantation and then followed-up accordingly. Each participating institution inputs data through a web-based case report form according to a standardized protocol. Between March 2015 and December 2017, a total of 112 patients received lung transplantation and were registered in the KOTRY database. Written informed consent is obtained from each patient prior to transplantation. If patients are unable to provide consent due to disease severity, informed consent is obtained from a relative or legal representative. This KOTRY study was reviewed and approved by the Institutional Ethics Committees of each participating organization.

The clinical data of 112 patients received lung transplantation during study period were followed up until June 2018. The entire cohort was divided into two groups: the control group $(n=85)$ comprised recipients who did not require ECMO before lung transplantation and the bridge-ECMO group $(n=27)$ comprised recipients who were bridged to lung transplantation with ECMO. Post-transplant outcomes, including primary graft dysfunction (PGD) assessed and graded by the International Society for Heart and Lung Transplantation lung transplant injury grades [19], functional status at discharge, graft function, and survival up to 48 months after lung transplantation were assessed.

\section{Data collection and clinical outcomes}

Information about transplant recipients, donors, transplant operations, and postoperative follow-up results were prospectively collected. Data for recipients including general demographic information, primary diagnosis, and pre-transplantation status, and data for donors including general demographic information, cause of brain death, and smoking status, were collected. Transplant surgery data including unilateral or bilateral lung transplantation, operation time, ischemic time, need for intraoperative hemodynamic support, and hemodynamic support type were collected. KOTRY also includes data about post-transplantation results including immediate complications, need for organ support, prevalence of primary graft dysfunction, serial pulmonary function, and outcomes such as the length of hospital stay, in-hospital and 6-month mortality, function status at discharge, and comorbidities. The most recent information for each patient was collected at 3, 6, 9, and 12 months after discharge, and then annually. The follow-up data were collected from patients by the attending physician and stored using the web-based case report form.

\section{Statistical analysis}

All data are presented as medians and interquartile ranges for continuous variables, and as numbers and percentages for categorical variables. We compared the clinical characteristics and outcomes of the two groups using the Mann-Whitney U test or Student's t-test, as appropriate, for continuous variables and the chi-square test or Fisher's exact test for categorical variables. Probability of survival curves for each group were estimated by the Kaplan-Meier method and compared by the logrank test. Data were analyzed using IBM SPSS Statistics for Windows, version 23.0 (Armonk, NY, USA). 


\section{Results}

\section{Baseline characteristics}

During the study period, a total of 112 patients underwent lung transplantation and were registered in KOTRY. The baseline characteristics of the patients are shown in Table 1. Among them, 71 $(63.4 \%)$ were male and the median age of all patients was 58.0 (interquartile range, IQR 52.5-62.0) years. Idiopathic pulmonary fibrosis $(53.6 \%)$ was the most common reason for lung transplantation, followed by connective tissue disease associated interstitial lung disease (17.9\%) and bronchiolitis obliterans after hematopoietic stem cell transplantation (8.9\%). One patient received simultaneous heart-lung transplantation due to Eisenmenger syndrome. All patients were receiving their first lung transplants. The pretransplant oxygenation with partial pressure of arterial oxygen $\left(\mathrm{PaO}_{2}\right) /$ fraction of inspired oxygen $\left(\mathrm{FiO}_{2}\right)$ ratio $\left(\mathrm{PaO}_{2} / \mathrm{FiO}_{2}\right.$ ratio) was 224.0 (IQR 125.0-281.0). Thirty-nine patients (34.8\%) received $\mathrm{MV}$ before lung transplantation and all patients in the bridge-ECMO group received MV simultaneously before lung transplantation. The median duration of bridging with ECMO was 11.0 (IQR 6.0-18.0) days in the bridge-ECMO group. Veno-venous mode $(n=$ $24,89 \%)$ was the most common type of ECMO used in ECMO-bridge group, followed by veno-venousarterial in two and veno-arterial in one. All but four of cannulation configurations for veno-venous ECMO was femoro-femoral cannulation.

The median age of donors was 41.5 (IQR 32.0-49.0) years and the most common cause of brain death was trauma (33.0\%). Forty-six (41.1\%) donors were current smokers. All organs were from deceased donors.

Table 1 Pre-transplant characteristics of lung transplant patients and donors

\begin{tabular}{|c|c|c|c|c|}
\hline & Overall $(N=112)$ & Bridge-ECMO group $(n=27)$ & Non-bridge-ECMO group $(n=85)$ & $p$ \\
\hline \multicolumn{5}{|l|}{ Demographics } \\
\hline Age, y & $58.0[52.5-62.0]$ & $58.0[53.0-62.0]$ & $58.0[52.0-62.0]$ & 0.859 \\
\hline Sex (Male) & $71(63.4 \%)$ & $21(77.8 \%)$ & $50(58.8 \%)$ & 0.121 \\
\hline $\mathrm{BMI}\left(\mathrm{kg} / \mathrm{m}^{2}\right)$ & $21.2[19.0-23.5]$ & $21.4[18.7-23.4]$ & $21.2[19.1-23.5]$ & 0.999 \\
\hline Primary diagnosis, n (\%) & & & & 0.187 \\
\hline Idiopathic pulmonary fibrosis & $60(53.6 \%)$ & $13(48.1 \%)$ & $47(55.3 \%)$ & \\
\hline Other fibrosis/Emphysema & $7(6.2 \%)$ & $1(3.7 \%)$ & $6(7.1 \%)$ & \\
\hline CTD related interstitial lung disease & $20(17.9 \%)$ & $5(18.5 \%)$ & $15(17.6 \%)$ & \\
\hline Bronchiolitis obliterans after HSCT & $10(8.9 \%)$ & $2(7.4 \%)$ & $8(9.4 \%)$ & \\
\hline Acute respiratory distress syndrome & $8(7.1 \%)$ & $5(18.5 \%)$ & $3(3.5 \%)$ & \\
\hline Others $^{a}$ & $7(6.2 \%)$ & $1(3.7 \%)$ & $6(7.1 \%)$ & \\
\hline \multicolumn{5}{|l|}{ Pre-transplantation status } \\
\hline $\mathrm{PaO} 2 / \mathrm{FiO} 2$ ratio & $224.0[125.0-281.0]$ & $110.0[82.5-251.0]$ & $229.0[181.0-288.0]$ & 0.008 \\
\hline LVEF, \% & $62.0[59.0-67.0]$ & $61.0[56.0-65.0]$ & $63.0[59.0-68.0]$ & 0.298 \\
\hline RVSP, $\mathrm{mmHg}$ & $50.0[41.0-66.0]$ & $61.0[47.0-88.0]$ & $48.5[40.5-64.5]$ & 0.141 \\
\hline Preoperative MV, n (\%) & $39(34.8 \%)$ & $27(100.0 \%)$ & $12(14.1 \%)$ & $<0.001$ \\
\hline Wait-list duration (day) & $69.5[18.5-127.5]$ & $27.0[10.5-40.5]$ & $87.0[35.0-145.0]$ & $<0.001$ \\
\hline \multicolumn{5}{|l|}{ Donor demographics } \\
\hline Sex (Male) & $66(58.9 \%)$ & $16(59.3 \%)$ & $50(58.8 \%)$ & 1.000 \\
\hline Age, y & $41.5[32.0-49.0]$ & $38.0[33.5-47.0]$ & $43.0[31.0-50.0]$ & 0.464 \\
\hline $\mathrm{BMI}\left(\mathrm{kg} / \mathrm{m}^{2}\right)$ & $22.1[20.1-24.2]$ & 20.9 [20.0-23.2] & $22.7[20.1-25.1]$ & 0.122 \\
\hline Donor cause of brain death, $n(\%)$ & & & & 0.053 \\
\hline Trauma & $37(33.0 \%)$ & $12(44.4 \%)$ & 25 (29.4\%) & \\
\hline Underlying disease progression & $27(24.1 \%)$ & $8(29.6 \%)$ & $19(22.4 \%)$ & \\
\hline Suicide & $25(22.3 \%)$ & $7(25.9 \%)$ & $18(21.2 \%)$ & \\
\hline Donor current smoker, n (\%) & $46(41.1 \%)$ & $7(25.9 \%)$ & 39 (45.9\%) & 0.043 \\
\hline
\end{tabular}

$B M I$ body mass index, CTD connective tissue disease, $H S C T$ hematopoietic stem cell transplantation, FEV1 forced expiratory volume in $1 \mathrm{~s}, P a O 2$ arterial oxygen tension, FiO2 fractional inspired oxygen, LVEF left ventricular ejection fraction, RVSP right ventricular systolic pressure, MV mechanical ventilation, ECMO extracorporeal membrane oxygenation

aOthers include 3 bronchiectasis patients, 2 lymphangioleiomyomatoses patients, one Eisenmenger syndrome patient who received both heart and lung transplants, and one secondary pulmonary arterial hypertension patient 


\section{Intra-operation characteristics}

The intra-operation characteristics of the enrolled patients are shown in Table 2. One hundred and eight (96.4\%) patients underwent bilateral lung transplantation. Total ischemic time for the right lung was 232.0 (IQR 180.0338.5) minutes and total ischemic time for the left lung was 305.0 (IQR 258.0-372.0) minutes. The median operation time of all patients was 480.0 (IQR 378.0-612.5) minutes. The median operation time in the bridge-ECMO group (575.0 min, IQR 474.0-690.0) was longer than in the control group (455.0 min, IQR 364.0-555.0) $(P<0.001)$. Seventy-nine $(70.5 \%)$ patients required mechanical support with ECMO during the operation.

\section{Post-transplantation outcomes}

After lung transplantation, immediate complications developed in $48(42.9 \%)$ patients (Table 3 ). The most common immediate complication was infection (35.4\%), followed by post operation bleeding (33.3\%). The frequency of immediate complications was not different between the bridge-ECMO group and nonbridge-ECMO group. However, postoperative length of stay in the intensive care unit was longer in the bridge-ECMO group (33.0 days, IQR 23.0-43.5) compared with the non-bridge-ECMO group (9.0 days, IQR 6.0-16.0) $(P<0.001)$. In addition, the time from transplantation to hospital discharge was longer in the bridge-ECMO group (46.0 days, IQR 38.5-68.5) compared with the non-bridge-ECMO group (35.0 days, IQR 25.0-67.0) $(P=0.030)$. The hospital mortality for all patients was $16.4 \%$, with no significant difference between the two groups $(25.9 \%$ in bridgeECMO group and $13.3 \%$ in non-bridge-ECMO group, $P=0.212)$. Partially dependent $(43.8 \%)$ was the most common functional status at discharge, followed by fully independent (33.9\%), and was not different between the two groups. The majority of patients (70.4\% of bridge-ECMO group and $77.6 \%$ of nonbridge-ECMO group) were discharged to their homes.
Only 5 patients (4.5\%) required tracheostomy at discharge.

As shown in Table 4, the prevalence of PGD was not significantly different between the bridge-ECMO group and non-bridge-ECMO group at $0 \mathrm{~h}, 24 \mathrm{~h}, 48 \mathrm{~h}$, and $72 \mathrm{~h}$ after lung transplantation $(P=0.255, P=0.481, P=0.817$, and $P=0.561$ respectively).

Survival rate at 6 months after lung transplantation was $75.9 \%$, and was not significantly different between the bridge-ECMO group (66.6\%) and non-bridge-ECMO group $(78.8 \%)(P=0.304)$. Bridging with ECMO prior to lung transplantation did not significantly affect overall survival (Fig. 1). Although the probability of survival for the bridge-ECMO group appeared to decrease in the first few months post-transplantation, this difference was not statistically significant $(P=0.139$, log-rank test). In addition, there were no significant differences in posttransplant lung function between the two groups at 3 months, 6 months, 9 months, 12 months, or 24 months postoperatively (Fig. 2).

\section{Discussion}

In this multicenter prospective observational study, we found that there were no significant differences in immediate postoperative complications, development and severity of PGD, functional status at discharge, longterm survival, or lung function in patients who received bridging with ECMO compared with the control group, despite longer operation time, longer ICU stay, and longer hospitalization after lung transplantation in the former group.

ECMO support improves outcomes in patients with life-threatening respiratory failure [11] and the application of ECMO as a rescue therapy is expanding in clinical practice [20]. In addition, ECMO has become a lifesaving intervention for a subset of rapidly deteriorating patients with end-stage lung disease, which offers optimizing gas exchange and end-organ perfusion to patients who might otherwise die before a suitable donor

Table 2 Intra-operative characteristics

\begin{tabular}{|c|c|c|c|c|}
\hline & Overall $(N=112)$ & Bridge-ECMO group $(n=27)$ & Non-bridge-ECMO group $(n=85)$ & p \\
\hline Bilateral lung transplantation, n (\%) & $108(96.4 \%)$ & $26(96.3 \%)$ & $82(96.5 \%)$ & 1.000 \\
\hline Operation Time, min & $480.0[378.0-612.5]$ & $575.0[474.0-690.0]$ & $455.0[364.0-555.0]$ & $<0.001$ \\
\hline Total ischemic time, right, min & $232.0[180.0-338.5]$ & $280.0[230.5-363.0]$ & $223.0[172.0-311.0]$ & 0.008 \\
\hline Total ischemic time, left, min & $305.0[258.0-372.0]$ & $331.0[250.0-372.0]$ & $300.0[259.0-372.0]$ & 0.849 \\
\hline Intraoperative CPB support, n (\%) & $36(32.1 \%)$ & $12(44.4 \%)$ & $24(28.2 \%)$ & 0.182 \\
\hline Intraoperative ECMO support, n (\%) & 79 (70.5\%) & $20(74.1 \%)$ & $59(69.4 \%)$ & 0.825 \\
\hline ECMO type, n (\%) & & & & $<0.001$ \\
\hline Veno-venous & $11(13.9 \%)$ & $9(45.0 \%)$ & $2(3.4 \%)$ & \\
\hline Veno-arterial & $68(86.1 \%)$ & $11(55.0 \%)$ & $57(96.6 \%)$ & \\
\hline
\end{tabular}

ECMO extracorporeal membrane oxygenation, $C P B$ cardiopulmonary bypass 
Table 3 Post-transplantation outcomes

\begin{tabular}{|c|c|c|c|c|}
\hline & $\begin{array}{l}\text { Overall } \\
(\mathrm{N}=112)\end{array}$ & $\begin{array}{l}\text { Bridge-ECMO } \\
\text { group }(n=27)\end{array}$ & $\begin{array}{l}\text { Non-bridge-ECMO } \\
\text { group }(n=85)\end{array}$ & $p$ \\
\hline Immediate complications ${ }^{\mathrm{a}}, \mathrm{n}(\%)$ & $48(42.9 \%)$ & $15(55.6 \%)$ & $33(38.8 \%)$ & 0.191 \\
\hline Post operation bleeding & $16(33.3 \%)$ & $7(46.7 \%)$ & $9(27.3 \%)$ & 0.322 \\
\hline Reoperation & 14 & 6 & 8 & \\
\hline Conservative management & 2 & 1 & 1 & \\
\hline Infection & $17(35.4 \%)$ & $4(26.7 \%)$ & $13(39.4 \%)$ & 0.597 \\
\hline Airway complication & $4(8.3 \%)$ & $2(13.3 \%)$ & $2(6.1 \%)$ & 0.778 \\
\hline Total ICU length of stay, day & $13.0[6.0-31.0]$ & $33.0[23.0-43.5]$ & $9.0[6.0-16.0]$ & $<0.001$ \\
\hline Time interval between transplantation and discharge, day & $39.0[26.5-67.0]$ & $46.0[38.5-68.5]$ & $35.0[25.0-67.0]$ & 0.030 \\
\hline Hospital mortality, n (\%) & $18(16.4 \%)$ & $7(25.9 \%)$ & $11(13.3 \%)$ & 0.212 \\
\hline Function status at discharge, n (\%) & & & & 0.295 \\
\hline Fully independent & $38(33.9 \%)$ & $10(37.0 \%)$ & $28(32.9 \%)$ & \\
\hline Partially dependent & $49(43.8 \%)$ & $8(29.6 \%)$ & $41(48.2 \%)$ & \\
\hline Fully dependent & $5(4.5 \%)$ & $2(7.4 \%)$ & $3(3.5 \%)$ & \\
\hline Tracheostomy at discharge, n (\%) & $5(4.5 \%)$ & $1(3.7 \%)$ & $4(4.7 \%)$ & 0.703 \\
\hline Final destination, n (\%) & & & & 0.405 \\
\hline Home & $85(75.9 \%)$ & 19 (70.4\%) & $66(77.6 \%)$ & \\
\hline Other hospital & $7(6.2 \%)$ & $1(3.7 \%)$ & $6(7.1 \%)$ & \\
\hline \multicolumn{5}{|l|}{ Developed co-morbidity ${ }^{\mathrm{b}}, \mathrm{n}(\%)$} \\
\hline Diabetes mellitus & $24(27.0 \%)$ & $5(27.8 \%)$ & $19(26.8 \%)$ & 1.000 \\
\hline Hypertension & $16(18.0 \%)$ & $3(16.7 \%)$ & $13(18.3 \%)$ & 1.000 \\
\hline PTLD & $1(1.1 \%)$ & $0(0.0 \%)$ & $1(1.4 \%)$ & 1.000 \\
\hline Cancer & $1(1.1 \%)$ & $0(0.0 \%)$ & $1(1.4 \%)$ & 1.000 \\
\hline CKD with hemodialysis & $3(2.7 \%)$ & $0(0.0 \%)$ & $3(3.5 \%)$ & 0.433 \\
\hline 6 months mortality, n (\%) & $27(24.1 \%)$ & 9 (33.3\%) & $18(21.2 \%)$ & 0.304 \\
\hline
\end{tabular}

ECMO extracorporeal membrane oxygenation, RRT renal replacement therapy, ICU intensive care unit, PTLD post-transplant lymphoproliferative disease a Immediate complication evaluated in ICU complication after lung transplantation

${ }^{\mathrm{b}}$ Co-morbidity evaluated at 6 months after lung transplantation

lung becomes available. Although bridging with ECMO is generally associated with a greater perioperative risk and poorer long-term survival [21], ECMO allows actively deteriorating and severely ill patients with endstage lung disease to remain eligible for lung transplantation.

During the last decade, several studies aimed to evaluate survival outcomes between bridge-ECMO patients and non-bridge-ECMO patients to demonstrate the efficacy of using ECMO as a bridge strategy. Toyoda et al. detected no survival difference between the bridge-ECMO group $(n=24)$ and non-bridge-ECMO group $(n=691)$ of $74 \%$ versus $83 \%$, respectively, at 1 year after transplantation [22]. Schechter et al. showed that 1-year survival was not different between bridge only with ECMO patients and control patients (70.4\% versus $84.2 \%)$ [23]. In contrast, Inci et al. showed worse overall and 3 month conditional survivals in the bridge-ECMO group $(n=26)$ versus the non-bridge-ECMO group $(n=160)$ (68\% versus $85 \%, p=$ $0.001 ; 86 \%$ versus $92 \%, p=0.03$, respectively) [15]. In the present study, the 6-month mortality of all patients was $24.1 \%$ and there was no significant difference between the bridge-ECMO group and non-bridge-ECMO group in this respect (33.3 and $21.2 \%, P=0.304$ ). The strength of our study is that recent, multi-institutional data for lung transplantation and a large sample of bridge-ECMO patients were included. These results indicate that bridging with ECMO is effective for patients awaiting lung transplantation due to the recent evolution of ICU care and ECMO management.

In this study, we also provide valuable information about short-term post transplantation outcomes. Despite technical improvements, ECMO is associated with risks of complications including hemolysis and need for transfusion, cardiovascular dysfunction, bleeding due to anticoagulation, and thrombosis formation. Furthermore, ICU admission for ECMO management leads to ICU-acquired weakness and infection associated with catheter or ICU care $[24,25]$. Our results indicate that post-operative bleeding (46.7\%) is the most common immediate 
Table 4 Prevalence of primary graft dysfunction after lung transplantation

\begin{tabular}{|c|c|c|c|c|}
\hline & Overall $(\mathrm{N}=112)$ & Bridge-ECMO group $(n=27)$ & Non-bridge-ECMO group $(\mathrm{n}=85)$ & $p$ \\
\hline $\mathrm{Oh}$ & & & & 0.255 \\
\hline PGD 0 & 89 (79.5\%) & $25(92.6 \%)$ & $64(75.3 \%)$ & \\
\hline PGD 1 & $1(0.9 \%)$ & $0(0.0 \%)$ & $1(1.2 \%)$ & \\
\hline PGD 2 & $6(5.4 \%)$ & $1(3.7 \%)$ & $5(5.9 \%)$ & \\
\hline PGD 3 & $16(14.3 \%)$ & $1(3.7 \%)$ & $15(17.6 \%)$ & \\
\hline $24 \mathrm{~h}$ & & & & 0.481 \\
\hline PGD 0 & 96 (85.7\%) & $25(92.6 \%)$ & 71 (83.5\%) & \\
\hline PGD 1 & $5(4.5 \%)$ & $1(3.7 \%)$ & $4(4.7 \%)$ & \\
\hline PGD 2 & $4(3.6 \%)$ & $1(3.7 \%)$ & $3(3.5 \%)$ & \\
\hline PGD 3 & $7(6.2 \%)$ & $0(0.0 \%)$ & $7(8.2 \%)$ & \\
\hline $48 \mathrm{~h}$ & & & & 0.817 \\
\hline PGD 0 & 99 (88.4\%) & $25(92.6 \%)$ & $74(87.1 \%)$ & \\
\hline PGD 1 & $5(4.5 \%)$ & $1(3.7 \%)$ & $4(4.7 \%)$ & \\
\hline PGD 2 & $6(5.4 \%)$ & $1(3.7 \%)$ & $5(5.9 \%)$ & \\
\hline PGD 3 & $2(1.8 \%)$ & $0(0.0 \%)$ & $2(2.4 \%)$ & \\
\hline $72 \mathrm{~h}$ & & & & 0.561 \\
\hline PGD 0 & 99 (88.4\%) & $25(92.6 \%)$ & $74(87.1 \%)$ & \\
\hline PGD 1 & $4(3.6 \%)$ & $0(0.0 \%)$ & $4(4.7 \%)$ & \\
\hline PGD 2 & 7 (6.2\%) & $2(7.4 \%)$ & 5 (5.9\%) & \\
\hline PGD 3 & $2(1.8 \%)$ & $0(0.0 \%)$ & $2(2.4 \%)$ & \\
\hline
\end{tabular}

$E C M O$ extracorporeal membrane oxygenation, $P G D$ primary graft dysfunction

complication in bridge-ECMO patients, while infection $(39.4 \%)$ is the most common in the non-bridge-ECMO group, although there were no significant differences in number of immediate complications after transplantation including post-operative bleeding, infection, and airway complications between the two groups. All patients but two showed feasible functional status at discharge and all patients but one were discharged home in the bridge-ECMO group.

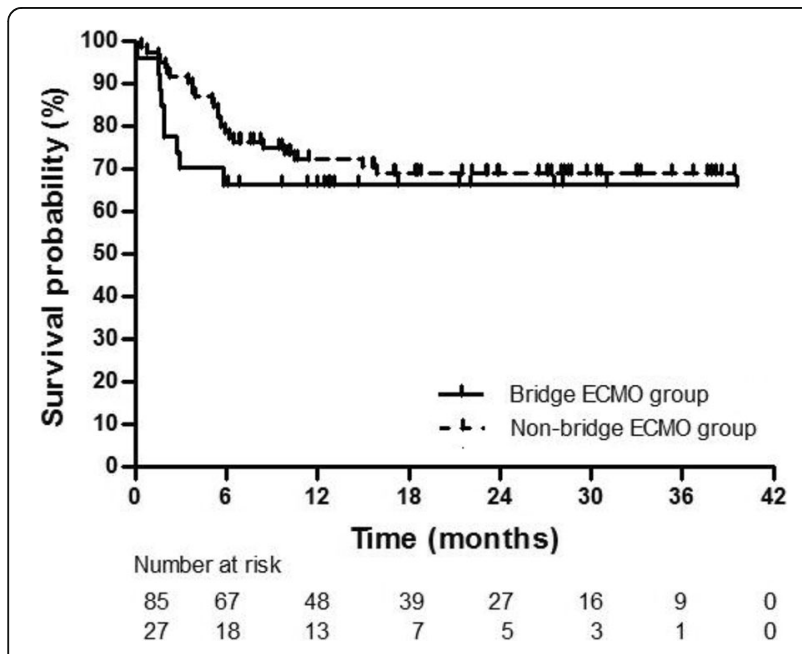

Fig. 1 Kaplan-Meier analysis of survival after lung transplantation
These results indicate that bridging with ECMO is feasible for patients awaiting lung transplantation by considering not only survival but also quality of life after discharge.

In the present study, the long-term outcomes of lung transplantation after bridging with ECMO were considered acceptable. KOTRY collects data for each patient serially at 3, 6, 9, 12 months after discharge, and then annually. However, our analysis includes only 2 years of follow-up data since the inclusion of lung transplant patients in KOTRY was initiated only in 2015. Pulmonary function, including predicted FEV1 and FVC, showed no significant differences between the bridge-ECMO group and non-bridge-ECMO group at 3 months, 6 months, 9 months, 12 months, or 24 months follow-up. Comorbidities including hypertension, diabetes, and maintenance hemodialysis that developed within 2 years after lung transplantation did not significantly differ between the two groups. These findings suggest that long-term prognosis for lung transplant patients after bridge ECMO is acceptable, if lung transplantation is successful.

Although the results of this study provide additional information on short- and long-term outcomes of lung transplantation after bridging with ECMO in a relatively large sample from a prospective multicenter registry, the study has several limitations that should be acknowledged. First, because of the observational 


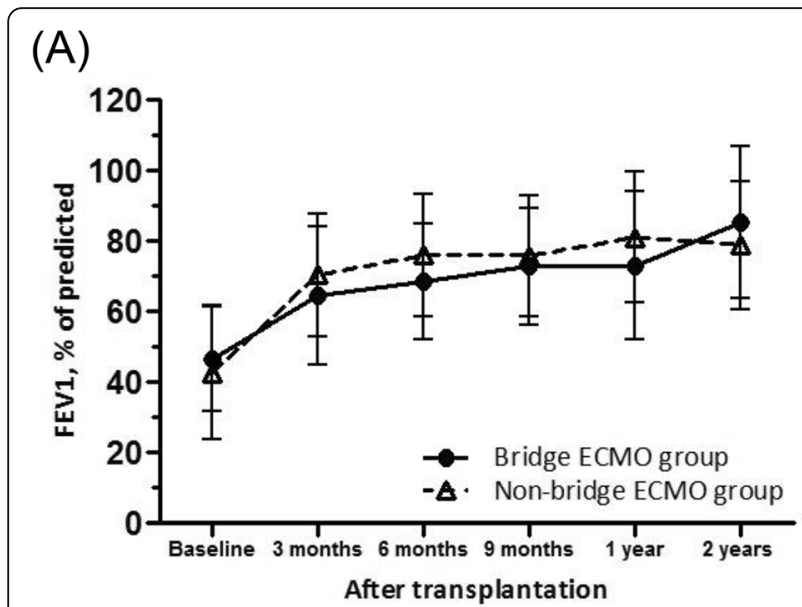

(B)

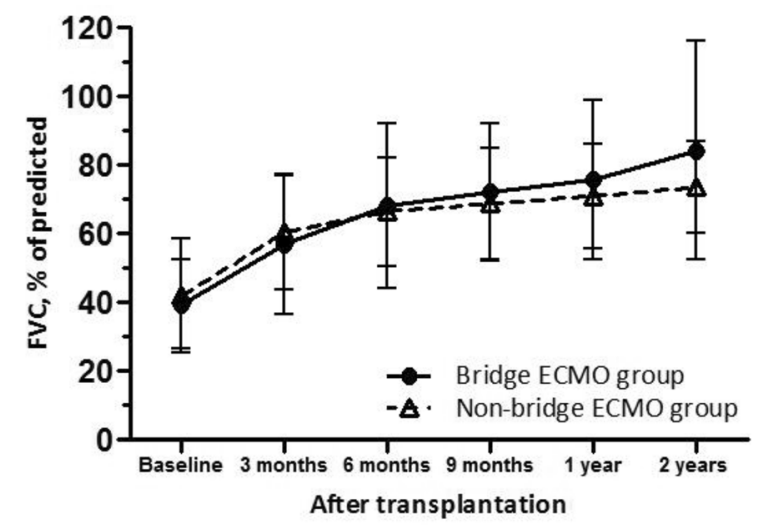

Fig. 2 Forced expiratory volume in $1 \mathrm{~s}\left(F E V_{1}\right)(A)$ and forced vital capacity $(F V C)(B)$, expressed as percent of predicted, after lung transplantation. Error bars depict the interquartile range of the median

nature of the study, our findings remain prone to various biases. We used a national multicenter designed to improve the generalizability of our findings, but there is a potential risk of selection bias. In addition, differences in pre-transplantation status between the two groups should be considered, which might influence the clinical outcomes. Although the bridge-ECMO group was more severely ill before transplantation, however, transplantation outcomes was comparable. Second, because KOTRY was designed to collect the follow up data of lung transplantation, detailed information on the clinical status prior to ECMO, ECMO management including case selection, and rehabilitation prior to transplantation was not systematically collected. Third, KOTRY includes a large number of bridge-ECMO patients compared to other studies [26-28]. The high rate of bridge with ECMO in our study may reflect the Korean lung allocation system based firstly on urgency of transplant [28], which is different from the European lung allocation score system based on the expected benefit after lung transplantation as well as the disease severity. Under a medical urgency-based allocation system regardless of post-transplant survival in Korea, therefore, patients with ECMO on waiting list are given the highest priority for transplantation. However, this is what allowed a large number of lung transplant patients who underwent bridging with ECMO to be enrolled. Fourth, KOTRY is not the only source of data regarding lung transplantation in Korea. Compared with the Korean Network for Organ Sharing data, only $49 \%$ of all patients who received lung transplantation in Korea during the study period were registered in the KOTRY. Finally, KOTRY enrolls patients at the time of transplantation, and we were unable to analyze patients who died while waiting for lung transplantation while on ECMO support.

\section{Conclusion}

In conclusion, lung transplantation after bridging with ECMO leads to acceptable patient outcomes. However, current evidence does not permit firm conclusions regarding the efficacy of bridging with ECMO and further systematic multicenter trials among carefully selected patients with end-stage lung disease are needed.

\section{Abbreviations}

ECMO: Extracorporeal membrane oxygenation; FEV1: Forced expiratory volume in $1 \mathrm{~s}$; FVC: Forced vital capacity; ICU: Intensive care unit;

KOTRY: Korean organ transplantation registry; PGD: Primary graft dysfunction

\section{Acknowledgements}

Not applicable.

\section{Authors' contributions}

REK conceived and designed the study, analyzed the data and drafted this manuscript. JGL, SYK, YTK, SMC, DHK, WHC, SIP, KWJ, HKK, and HCP contributed to the design of this study, analysis of the data, and revising of the manuscript. KJ conceived and designed the study, analyzed the data, and wrote the final manuscript. All authors have read and approved the final manuscript.

\section{Funding}

This work was supported by a fund (2014-ER6301-00, 2014-ER6301-01, 2014ER6301-02, 2017-ER6301-00) by Research of Korea Centers for Disease Control and Prevention.

\section{Availability of data and materials}

The data that support the findings of this study are available on request from the corresponding author. The data are not publicly available due to privacy or ethical restrictions.

\section{Ethics approval and consent to participate}

The Institutional Review Boards of each participating organization approved this study. Written informed consent is obtained from each patient prior to transplantation. 


\section{Consent for publication}

Not applicable.

\section{Competing interests}

The authors declare that they have no competing interests.

\section{Author details}

'Department of Critical Care Medicine, Samsung Medical Center, Sungkyunkwan University School of Medicine, Seoul, Korea. ${ }^{2}$ Department of Thoracic and Cardiovascular Surgery, Severance Hospital, Yonsei University College of Medicine, Seoul, Korea. ${ }^{3}$ Division of Pulmonary and Critical Care Medicine, Department of Internal Medicine, Severance Hospital, Yonsei University College of Medicine, Seoul, Korea. ${ }^{4}$ Department of Thoracic and Cardiovascular Surgery, Seoul National University Hospital, Seoul National University College of Medicine, Seoul, Korea. ${ }^{5}$ Division of Pulmonary and Critical Care Medicine, Department of Internal Medicine, Seoul National University Hospital, Seoul National University College of Medicine, Seoul, Korea. ${ }^{6}$ Department of Thoracic and Cardiovascular Surgery, Pusan National University YangSan Hospital, Gyeongsangnam-do, Korea. 'Department of Pulmonology and Critical Care Medicine, Pusan National University YangSan Hospital, Gyeongsangnam-do, Korea. ${ }^{8}$ Department of Thoracic and Cardiovascular Surgery, Asan Medical Center, University of Ulsan College of Medicine, Seoul, Korea. ${ }^{9}$ Department of Pulmonary and Critical Care Medicine, Asan Medical Center, University of Ulsan College of Medicine, Seoul, Korea. ${ }^{10}$ Department of Thoracic and Cardiovascular Surgery, Samsung Medical Center, Sungkyunkwan University School of Medicine, Seoul, South Korea. ${ }^{11}$ Division of Pulmonary and Critical Care Medicine, Department of Medicine, Samsung Medical Center, Sungkyunkwan University School of Medicine, 81 Irwon-ro, Gangnam-gu, Seoul 06351, Korea.

Received: 16 September 2019 Accepted: 8 January 2020 Published online: 13 January 2020

\section{References}

1. Kotloff RM, Thabut G. Lung transplantation. Am J Respir Crit Care Med. 2011; 184:159-71.

2. Arcasoy SM, Kotloff RM. Lung transplantation. N Engl J Med. 1999;340:1081-91.

3. Yeo HJ, Yoon SH, Lee SE, Jeon D, Kim YS, Cho WH, et al. Current status and future of lung donation in Korea. J Korean Med Sci. 2017;32:1953-8.

4. Klein AS, Messersmith EE, Ratner LE, Kochik R, Baliga PK, Ojo AO. Organ donation and utilization in the United States, 1999-2008. Am J Transplant. 2010;10:973-86.

5. Hoeper MM, Granton J. Intensive care unit management of patients with severe pulmonary hypertension and right heart failure. Am J Respir Crit Care Med. 2011;184:1114-24.

6. Kalanuria AA, Ziai W, Mirski M. Ventilator-associated pneumonia in the ICU. Crit Care 2014:18:208.

7. Katira BH, Giesinger RE, Engelberts D, Zabini D, Kornecki A, Otulakowski G, et al. Adverse heart-lung interactions in ventilator-induced lung injury. Am J Respir Crit Care Med. 2017;196:1411-21.

8. Slutsky AS, Ranieri VM. Ventilator-induced lung injury. N Engl J Med. 2013; 369:2126-36.

9. Mason DP, Thuita L, Nowicki ER, Murthy SC, Pettersson GB, Blackstone EH. Should lung transplantation be performed for patients on mechanical respiratory support? The US experience. J Thorac Cardiovasc Surg. 2010;139: 765-73.e1.

10. Singer JP, Blanc PD, Hoopes C, Golden JA, Koff JL, Leard LE, et al. The impact of pretransplant mechanical ventilation on short- and long-term survival after lung transplantation. Am J Transplant. 2011;11:2197-204.

11. Peek GJ, Mugford M, Tiruvoipati R, Wilson A, Allen E, Thalanany MM, et al. Efficacy and economic assessment of conventional ventilatory support versus extracorporeal membrane oxygenation for severe adult respiratory failure (CESAR): a multicentre randomised controlled trial. Lancet. 2009;374 1351-63.

12. Javidfar J, Bacchetta M. Bridge to lung transplantation with extracorporeal membrane oxygenation support. Curr Opin Organ Transplant. 2012;17:496-502

13. Tipograf Y, Salna M, Minko E, Grogan EL, Agerstrand C, Sonett J, et al. Outcomes of Extracorporeal Membrane Oxygenation as a Bridge to Lung Transplantation. Ann Thorac Surg. 2019;107(5):1456-63.
14. Hayanga JW, Aboagye JK, Hayanga HK, Luketich JD, D'Cunha J. Extracorporeal membrane oxygenation as a bridge to lung retransplantation: is there a role? J Heart Lung Transplant. 2016;35:901-5.

15. Inci I, Klinzing S, Schneiter D, Schuepbach RA, Kestenholz P, Hillinger S, et al. Outcome of extracorporeal membrane oxygenation as a bridge to lung transplantation: an institutional experience and literature review. Transplantation. 2015;99:1667-71.

16. Makdisi G, Wang IW. Extra corporeal membrane oxygenation (ECMO) review of a lifesaving technology. J Thorac Dis. 2015;7:E166-76.

17. Chiumello D, Coppola S, Froio S, Colombo A, Del Sorbo L. Extracorporeal life support as bridge to lung transplantation: a systematic review. Crit Care. 2015;19:19.

18. Lee JG, Kim SY, Kim YT, Lee HJ, Park S, Choi SM, et al. First report of the Korean lung transplantation registry. Transplant Proc. 2018;50:2759-63.

19. Christie JD, Carby M, Bag R, Corris P. Hertz M, Weill D. Report of the ISHLT working group on primary lung graft dysfunction part II: definition. A consensus statement of the International Society for Heart and Lung Transplantation. J Heart Lung Transplant. 2005;24:1454-9.

20. Thiagarajan RR, Barbaro RP, Rycus PT, McMullan DM, Conrad SA, Fortenberry $J$, et al. Extracorporeal life support organization registry international report 2016. ASAIO J. 2017;63:60-7.

21. Gupta P, McDonald R, Chipman CW, Stroud M, Gossett JM, Imamura M, et al. 20-year experience of prolonged extracorporeal membrane oxygenation in critically ill children with cardiac or pulmonary failure. Ann Thorac Surg. 2012;93:1584-90.

22. Toyoda Y, Bhama JK, Shigemura N, Zaldonis D, Pilewski J, Crespo M, et al. Efficacy of extracorporeal membrane oxygenation as a bridge to lung transplantation. J Thorac Cardiovasc Surg. 2013;145:1065-70 discussion 70-1.

23. Schechter MA, Ganapathi AM, Englum BR, Speicher PJ, Daneshmand MA, Davis RD, et al. Spontaneously breathing extracorporeal membrane oxygenation support provides the optimal bridge to lung transplantation. Transplantation. 2016;100:2699-704

24. van Vught LA, Klein Klouwenberg PM, Spitoni C, Scicluna BP, Wiewel MA, Horn J, et al. Incidence, risk factors, and attributable mortality of secondary infections in the intensive care unit after admission for sepsis. JAMA. 2016; 315:1469-79.

25. Kress JP. Hall JB. ICU-acquired weakness and recovery from critical illness. N Engl J Med. 2014;370:1626-35.

26. Hayanga AJ, Aboagye J, Esper S, Shigemura N, Bermudez CA, D'Cunha J, et al. Extracorporeal membrane oxygenation as a bridge to lung transplantation in the United States: an evolving strategy in the management of rapidly advancing pulmonary disease. J Thorac Cardiovasc Surg. 2015;149:291-6.

27. Gulack BC, Hirji SA, Hartwig MG. Bridge to lung transplantation and rescue post-transplant: the expanding role of extracorporeal membrane oxygenation. J Thorac Dis. 2014;6:1070-9.

28. Yu WS, Kim SY, Kim YT, Lee HJ, Park S, Choi SM, et al. Characteristics of lung allocation and outcomes of lung transplant according to the Korean urgency status. Yonsei Med J. 2019;60:992-7.

\section{Publisher's Note}

Springer Nature remains neutral with regard to jurisdictional claims in published maps and institutional affiliations.

Ready to submit your research? Choose BMC and benefit from

- fast, convenient online submission

- thorough peer review by experienced researchers in your field

- rapid publication on acceptance

- support for research data, including large and complex data types

- gold Open Access which fosters wider collaboration and increased citations

- maximum visibility for your research: over $100 \mathrm{M}$ website views per year

At BMC, research is always in progress.

Learn more biomedcentral.com/submissions 